\title{
Aplikasi Mobile Money Management Dengan Fitur Optical Character Recognition Menggunakan Framework React Native
}

\author{
Susana ${ }^{*}$, Genrawan Hoendarto ${ }^{2}$ \\ 1,2 Universitas Widya Dharma Pontianak \\ *susana@widyadharma.ac.id
}

\begin{abstract}
Financial management is one of the important things in the process of achieving the financial goals of a person or an organization. Everyone has their own way to manages finances, this is dependent on the character and they goals. Financial management can be done conventionally, for example by manual method which is commonly done by write the expenses, income, and savings in a notebook. However, if the note must contain details of the transactions carried out, it can be considered less efficient. The use of Optical Character Recognition will be able to answer this problem, by taking a picture of the transaction, all transaction details will be recorded on the smartphone, and the user can validate the results obtained and save the record on the smartphone user. Users can also immediately see the total transactions made according to the selected time range without having to calculate each transaction made manually. The application will be designed using the react native framework which allows it to run on various platforms.
\end{abstract}

Keywords: money management, optical character recognition, react native

\begin{abstract}
Abstrak
Manajemen keuangan merupakan salah satu hal yang penting dalam proses mencapai tujuan finansial seseorang maupun sebuah organisasi. Cara setiap individu mengelola keuangan sangat bergantung pada karakter serta tujuan masing-masing individu. Pengelolaan keuangan dapat dilakukan secara konvensional, misalnya dengan cara manual yang umum dilakukan yaitu mencatat pengeluaran, pendapatan dan tabungan pada buku catatan. Namun, apabila catatan harus memuat detail-detail transaksi yang dilakukan, hal tersebut dapat dianggap kurang efisien. Penggunaan Optical Character Recognition akan dapat menjawab permasalah tersebut, yakni dengan mengambil gambar transaksi, maka semua detail transaksi akan tercatat pada smartphone, dan pengguna dapat melakukan validasi hasil yang diperoleh serta menyimpan catatan tersebut pada smartphone pengguna. Pengguna juga dapat langsung melihat total transaksi yang dilakukan sesuai dengan rentang waktu yang dipilih tanpa harus menghitung setiap transaksi yang dilakukan secara manual. Aplikasi akan dirancang dengan menggunakan framework react native yang memungkinkan untuk dijalankan pada berbagai platform.
\end{abstract}

Kata kunci: manajemen keuangan, optical character recognition, react native

\section{Pendahuluan}

\subsection{Latar Belakang}

Manajemen keuangan merupakan salah satu unsur penting dalam mencapai tujuan finansial. Manajemen keuangan diperlukan untuk menjaga kesehatan keuangan agar konsisten terhadap tujuan dan cita-cita pribadi atau bisnis. Manajemen keuangan berkaitan dengan aktivitas keuangan seperti: pemasukan, pengeluaran, perencanaan, hingga kegiatan menabung.
Banyak orang tidak melakukan manajemen keuangan dengan baik sehingga tujuan dan cita-cita pribadi atau bisnis tidak terwujud. Tujuan pribadi atau bisnis dapat dicapai jika pemasukan dan pengeluaran dapat dikelola dengan baik. Salah satu bentuk pengelolaan pemasukan dan pengeluaran adalah dengan merencanakan atau menetapkan targetnya.

Setiap orang yang ingin mencapai tujuan finansial masing-masing dapat 
mengelola keuangannya dengan cara konvensional seperti membuat pencatatan di sebuah buku kemudian membuatkan detail pengelolaannya. Akan tetapi, cara konvensional memiliki beberapa kekurangan seperti: kurangnya efisiensi waktu jika mencatat item dalam jumlah besar, catatan atau hitungan yang dibuat kurang akurat, rawan terjadi kehilangan dan tidak adanya feedback dari pengelolaan keuangan tersebut. Oleh karena itu, diperlukan cara lain yang dapat mengatasi kekurangan tersebut.

Optical Character Recognition (OCR) dapat memudahkan user untuk mencatat pemasukan dan pengeluarannya dengan gambar digital, sehingga dapat menghemat waktu user untuk melakukan pencatatan. OCR juga memerlukan perangkat berbasis Android untuk mengoperasikannya.

Perangkat berbasis Android saat ini sudah menjadi perangkat umum di masyarakat. Penggunaan perangkat berbasis Android memiliki tujuannya masing-masing untuk setiap orang, seperti bisnis, belajar, hiburan hingga manajemen keuangan. Selain itu, perangkat berbasis Android juga dapat menyimpan dan memproses pencatatan yang dilakukan oleh user. Hasil pemrosesan yang dilakukan oleh perangkat berbasis Android dapat diterima kembali oleh user sebagai feedback. Oleh karena itu, pengelolaan keuangan melalui perangkat berbasis android ini akan sangat memudahkan user.

\subsection{Tinjauan Pustaka}

\subsubsection{Penelitian Terdahulu}

Penelitian tentang aplikasi manajemen keuangan telah dilakukan oleh beberapa pihak, salah satunya adalah penelitian yang dilakukan oleh Noor dan Hadi pada tahun 2019. Penelitian tersebut menghasilkan aplikasi manajemen keuangan berbasis web yang digunakan oleh Dinas Komunikasi dan Informatika (Diskominfo) Kabupaten Tanah Laut. Aplikasi tersebut mempermudah bagian keuangan untuk memanajemen data keuangan secara lebih efektif dan efisien. Selain itu, aplikasi tersebut juga memudahkan pembuatan kwitansi belanja kegiatan DPA pada Diskominfo Kabupaten Tanah Laut.[1]

Penelitian sejenis juga dilakukan oleh Arka, Brata dan Brata pada tahun 2019. Penelitian tersebut menghasilkan aplikasi mobile manajemen keuangan yang dikembangkan dengan metode Scrum. Salah satu fitur unggulan pada aplikasi manajemen keuangan yang dihasilkan adalah fitur reminder batas harian. Fitur reminder akan memberikan notifikasi jika jumlah pengeluaran mendekati batas maksimum harian yang telah ditentukan sebelumnya [2].

\subsubsection{Landasan Teori}

Manajemen keuangan adalah segala aktivitas yang berhubungan dengan perolehan, pendanaan dan pengelolaan dengan beberapa tujuan secara menyeluruh untuk dapat mencapai tujuan yang diinginkan [3].

Optical character recognition (OCR) adalah proses pengklasifikasian pola optik yang terkandung di sebuah gambar digital secara otomatis gambar dari skrip tulisan tangan dan dikirim ke dalam karakter yang sesuai dengan alfanumerik atau karakter lain, yang sudah dikenali [4]-[5].

Android adalah sistem operasi berbasis Linux yang dirancang untuk perangkat seluler layar sentuh seperti smartphone dan komputer tablet [6].

React Native adalah framework untuk menulis aplikasi mobile yang real dan mendekati native untuk iOS dan Android. React Native ditulis dengan JavaScript dengan tujuan fungsionalitas dan integrasi seluler asli. Dibuat berdasarkan React, library JavaScript milik Facebook untuk membangun tampilan antarmuka pengguna, react native lebih menargetkan platform mobile daripada browser. Hal ini menunjukkan bahwa react native mengizinkan pengembang web untuk menulis aplikasi mobile yang tampak mendekati native. React Native juga ditulis sebagai ReactJS atau React.js, yang dirilis pada 2015 dan dirancang untuk pengembangan perangkat lunak seluler native [7]-[8]. 
JavaScript adalah bahasa pemrograman tingkat tinggi yang sudah diinterpretasi. Bahasa ini tidak perlu dijalankan melalui compiler sebelum komputer dapat menjalankan programnya. JavaScript Object Notation (JSON atau biasanya dibaca Jason) adalah sebuah format serialisasi data berbasis teks ringan yang dirancang untuk pertukaran data sehingga dapat dibaca oleh manusia [9][11].

\section{Metode Penelitian}

\subsection{Rancangan Penelitian}

Rancangan Penelitian yang digunakan penulis dalam penelitian ini adalah penelitian deskriptif, yang membuat deskripsi secara sistematis, faktual, dan akurat mengenai fakta-fakta yang terjadi pada objek penelitian.

\subsection{Pengumpulan Data}

Metode pengumpulan data yang dilakukan adalah dengan mengumpulkan informasi dari studi dokumen, buku, dan literatur. Informasi yang didapat adalah teoriteori yang mendasari penelitian dan akan diteliti oleh penulis.

\subsection{Analisis}

Teknik analisis data yang digunakan penulis dalam merancang system informasi katalog ini adalah dengan menggunakan Unified Modelling Language (UML) yaitu teknik pengembangan sistem yang menggunakan bahasa grafis sebagai alat untuk pendokumentasian dan melakukan spesifikasi pada sistem. Diagram yang digunakan yaitu use case diagram, activity diagram dan sequence diagram. Use case diagram merupakan permodelan untuk kelakuan (behavior) sistem informasi yang akan dibuat. Use case mendeskripsikan sebuah interaksi antara satu atau lebih aktor dengan sistem informasi yang akan dibuat. Activity diagram menggambarkan workflow (aliran kerja) atau aktivitas dari sebuah sistem atau proses bisnis atau menu yang ada pada perangkat lunak. Sequence diagram menggambarkan kelakuan objek pada use case dengan mendeskripsikan waktu hidup objek dan message yang dikirmkan dan diterima antar objek [12].

\subsection{Perancangan}

Dalam merancang aplikasi money management ini, penulis menggunakan framework React Native dengan menggunakan bahasa pemrograman Javascript. Dalam perancangan database aplikasi ini, penulis menggunakan Firebase Realtime Database.

Dengan React Native, pengembang aplikasi tidak perlu membuat aplikasi hybrid karena aplikasi yang dibuat dapat dikompilasi ke native code pada Android maupun iOS. Aplikasi yang dihasilkan berjalan di javascript runtime, dan dalam Real aplikasi, pada platform android akan di-compile ke java sedangkan pada IOS akan di-compile ke Objective-C. Dalam penelitian ini, penulis membuat real aplikasi yang dijalankan pada platform Android.

React Native bekerja dengan dengan menanamkan file Javascript yang sudah dibundle di dalam aplikasi, dan menjalankannya secara local dari aplikasi yang dibuat. Namun file Javascript juga dapat diletakan di dalam server dan diambil ketika ada koneksi. Hal ini memungkinkan pengembang untuk melakukan update aplikasi secara cepat tanpa melalu proses submit ke Google Playstore atapun iOS Appstore [7].

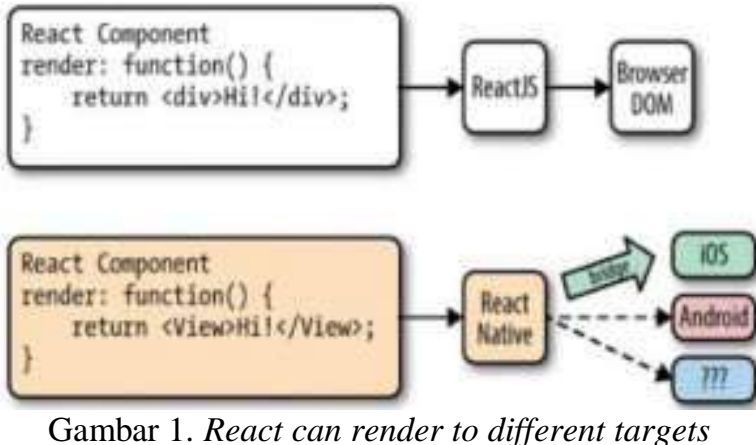

Jenis-Jenis Lifecycle React Native;

1) Initialization adalah sebuah siklus React Native untuk mengatur State dan Props sebelum aplikasi dijalankan 
2) Mounting adalah sebuah siklus ketika aplikasi baru saja dibuka. Ada 2 jenis mounting yaitu componentDidMount() yang memuat aplikasi sebelum render dilakukan dan componentWillMount yaitu siklus setelah proses render dilakukan menggunakan componentDidmount().

3) Updatating yaitu proses mengubah data yang telah di-mounting.

4) Unmount adalah proses menghancurkan atau men-destroy komponen yang sebelumnya didefinisikan.

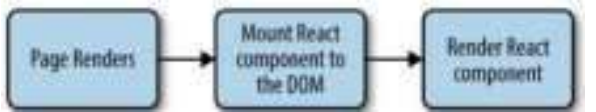

Gambar 2. Mounting components in React

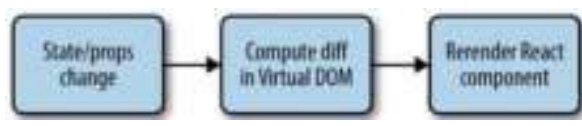

Gambar 3. Rerendering components in React

\section{Hasil Penelitian}

\subsection{Analisis Sistem}

Pada aplikasi money management, user dapat melakukan pencatatan transaksi keuangan untuk pemasukan dan pengeluaran. Kegiatan pencatatan data transaksi keuangan pada aplikasi ini dapat dilakukan dengan cara mengisi manual atau menggunakan Optical Character Recognition. Data transaksi keuangan user akan disimpan ke database dan dapat digunakan di waktu yang akan mendatang. Aplikasi menyediakan fitur untuk melihat data transaksi keuangan user yang sudah diolah dalam tempo harian, mingguan atau bulanan berdasarkan data transaksi yang telah disimpan user sebelumnya. Selain itu, aplikasi juga menyediakan fitur untuk melihat statistik transaksi keuangan user dalam tempo harian, mingguan atau bulanan dan dapat membandingkan dua statistik transaksinya dengan menggunakan fitur perbandingan.

Pada aplikasi ini terdapat fitur perencanaan yang terdiri dari dua kegiatan perencanaan, yaitu perencanaan pemasukan dan perencanaan keluaran untuk setiap bulan.

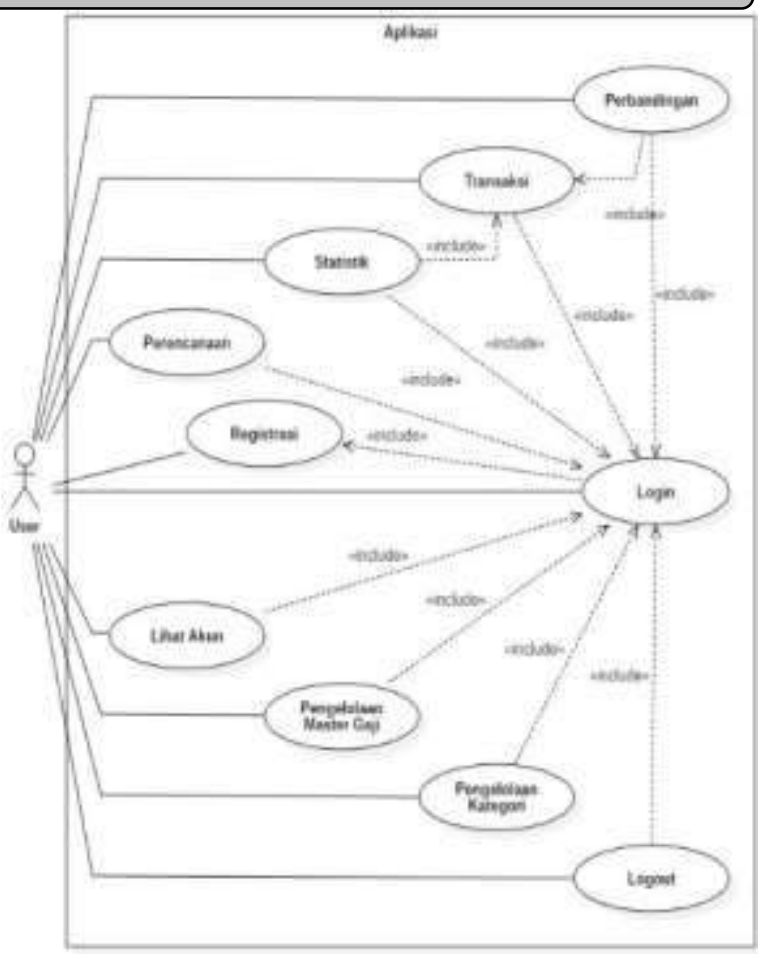

Gambar 4. Use Case Diagram

Aplikasi money management mengharuskan user untuk melakukan proses login terlebih dahulu agar dapat mengakses fitur lainnya. Jika user belum memiliki akun, maka user belum dapat melakukan proses login sehingga user perlu melakukan pembuatan akun pada form registrasi dengan memilih pilihan registrasi yang terdapat pada form login. Jika user sudah memiliki akun, maka user dapat melakukan proses login dengan memasukkan username dan password ke form login.

\subsubsection{Proses Registrasi}

Pada Gambar 5 terlihat bahwa saat user menekan pilihan registrasi pada form login, aplikasi akan menampilkan form registrasi. Kemudian user dapat mengisikan data registrasi dan menekan tombol register. Setelah menekan tombol register, aplikasi akan melakukan validasi data registrasi.

Jika masukan data registrasi tidak valid, maka aplikasi akan menampilkan pesan kesalahan masukan kepada user dan user dapat menekan tombol "OK". Setelah itu user dapat melakukan pengisian data registrasi kembali. Jika masukan data registrasi valid, maka aplikasi akan melanjutkan pengecekan data registrasi pada database. 


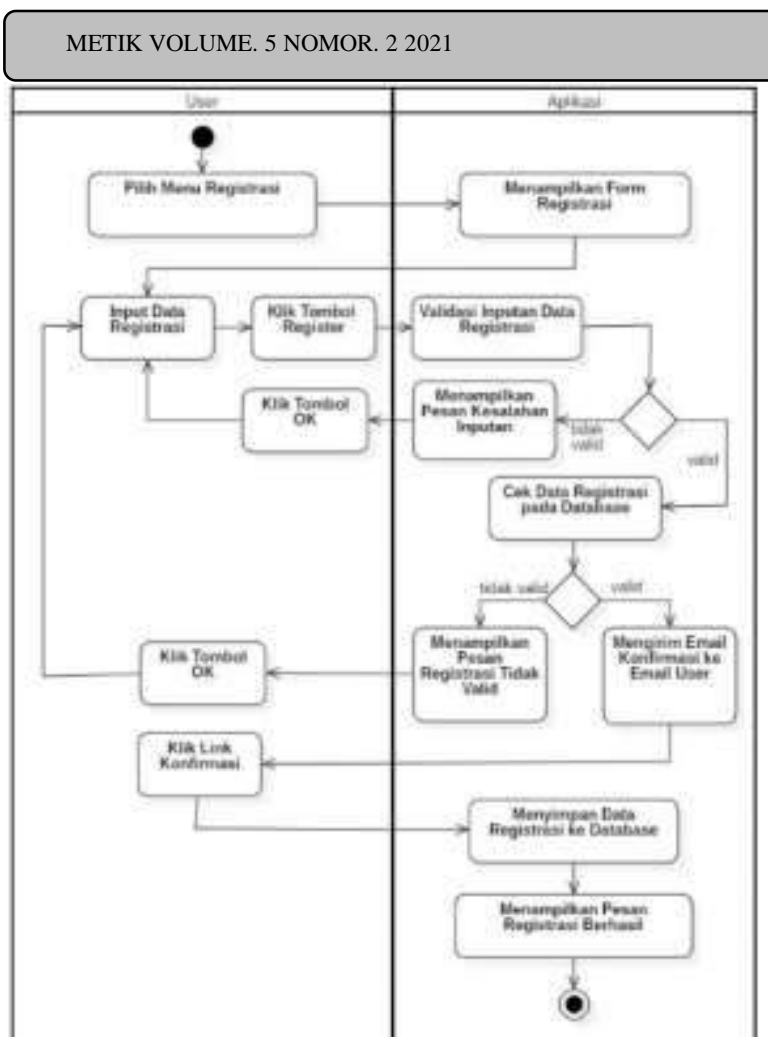

Gambaar 5. Activity Diagram Registrasi

Jika pengecekan data registrasi pada database tidak valid, maka aplikasi akan memberi pesan kepada user bahwa registrasi tidak valid dan user dapat menekan tombol "OK" untuk dapat mengisi data registrasi kembali. Jika valid, aplikasi akan mengirim link konfirmasi ke email user dan user dapat menekan link tersebut untuk mengkonfirmasi akunnya. Setelah itu, aplikasi akan menyimpan data registrasi user ke database dan yang terakhir aplikasi akan menampilkan pesan kepada user bahwa registrasi berhasil.

Pada Gambar 6 terlihat bahwa ketika user menjalankan aplikasi, aplikasi akan mengecek status login dan menampilkan form login jika status login adalah belum login. Saat user menekan tombol registrasi, form login akan memanggil form registrasi. Setelah itu, user dapat mengisi data registrasinya. Setelah user menekan tombol register, form registrasi akan melakukan validasi terhadap masukan data registrasi. Jika tidak valid, aplikasi akan memberikan pesan bahwa data registrasi tidak valid dan akan menampilkan form registrasi kembali. Jika email sudah pernah dipakai, maka aplikasi akan mengirim pesan bahwa data registrasi tidak valid ke $u$ ser dan akan menampilkan form registrasi

kembali. Jika email belum pernah dipakai, maka aplikasi akan mengirimkan link konfirmasi registrasi ke email user. Setelah user menekan link konfirmasi pada email, maka aplikasi akan menyimpan data registrasi ke database dan menampilkan pesan kepada user bahwa registrasi berhasil.

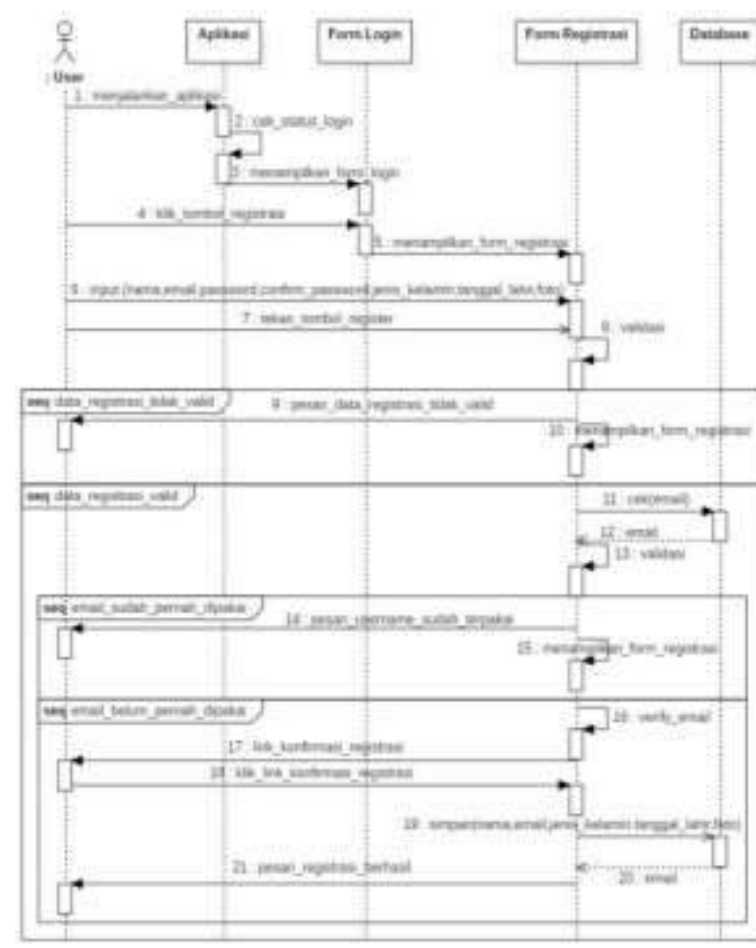

Gambar 6. Sequence Diagram Registrasi

\subsubsection{Proses Transaksi}

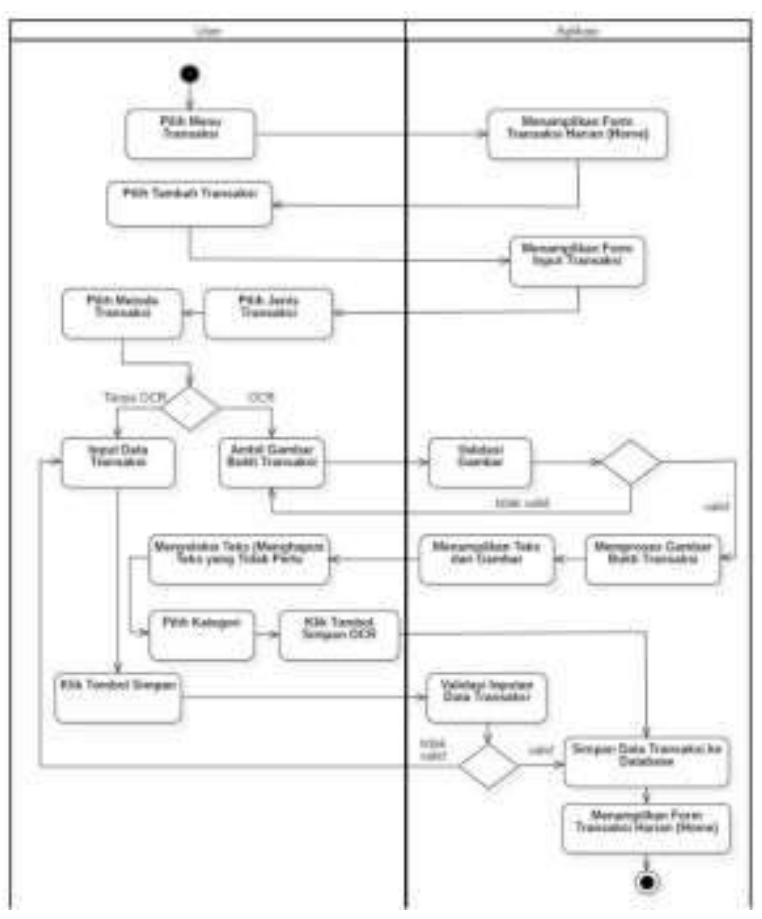

Gambar 7. Activity Diagram Transaksi 
Saat user menekan menu transaksi, aplikasi akan menampilkan form transaksi harian atau form menu utama. Di dalam form menu utama terdapat tombol tambah transaksi. Setelah user menekan tombol tambah transaksi, aplikasi akan menampilkan form input transaksi dan meminta user untuk memilih jenis transaksi yang terdiri dari income dan expenses. Setelah itu, user dapat memilih metode transaksi yang terdiri dari mengisi manual atau menggunakan OCR.

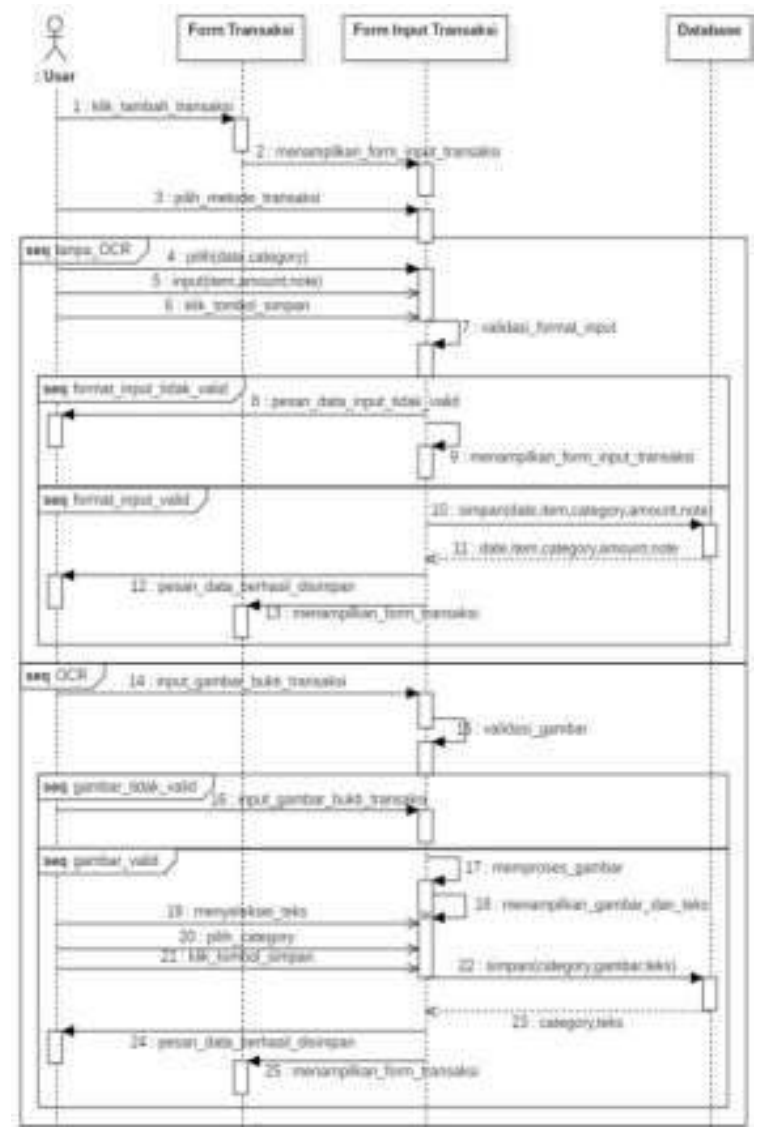

Gambar 8. Sequence Diagram Transaksi

Jika user menggunakan metode manual, user dapat mengisi data transaksinya yang terdiri dari tanggal, item, category, amount, dan note serta menekan tombol simpan. Setelah menekan tombol simpan, aplikasi akan melakukan validasi terhadap data transaksi. Jika tidak valid, maka aplikasi akan menampilkan pesan data input tidak valid kepada user. Jika valid, maka aplikasi akan menyimpan data transaksi dan menampilkan pesan bahwa transaksi berhasil disimpan kepada user.
Jika user menggunakan metode OCR, user dapat memasukkan gambar bukti transaksi ke dalam aplikasi. Setelah itu aplikasi akan melakukan validasi terhadap gambar tersebut. Jika tidak valid, user dapat langsung memasukkan ulang gambar bukti transaksinya, namun apabila gambar valid, maka aplikasi akan memproses gambar tersebut kemudian aplikasi akan menampilkan hasil prosesnya ke user untuk diolah. Setelah itu, user hanya memilih category dan menekan tombol simpan. Setelah user menekan tombol simpan, maka aplikasi akan menyimpan data transaksi yang berupa category, gambar, dan hasil OCR yang berupa teks ke database. Setelah itu, aplikasi akan menampilkan pesan bahwa data transaksi berhasil disimpan dan menampilkan form transaksi kembali.

\subsection{Rancangan Aplikasi Money \\ Management}

Pada rancangan form registrasi, terdapat isian username, email, password, confirm password, gender, date of birth, icon foto untuk memasukkan foto yang akan ditampilkan pada halaman profil dan tombol simpan.

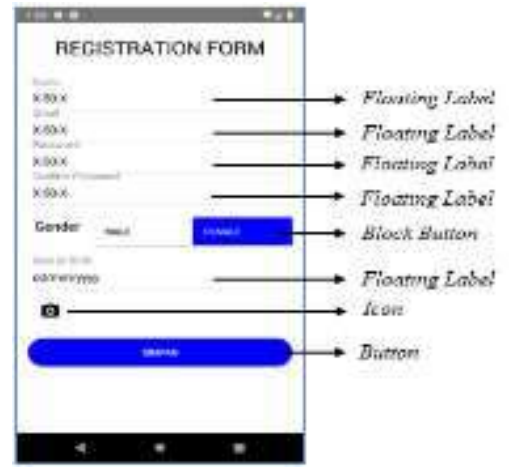

Gambar 9. Rancangan Form Registrasi

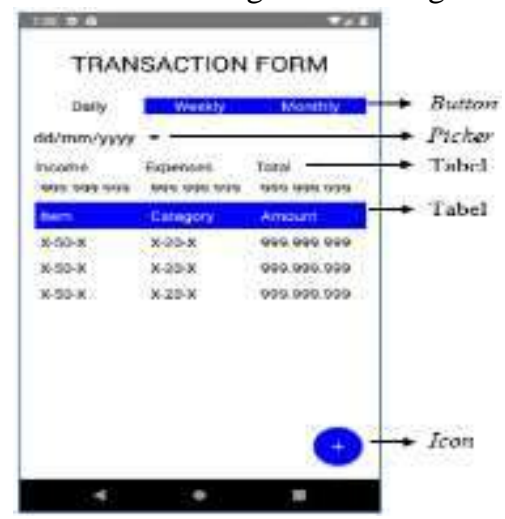


Gambar 10. Rancangan Form Transaksi

Pada rancangan form transaksi, terdapat tombol yang menunjukkan kelompok waktu transaksi, berupa transaksi harian, mingguan maupun bulanan. Selain itu terdapat picker untuk menampilkan rentang waktu yang dipilih user. Pada transaksi harian, akan ditampilkan income, expenses, total, item, category dan amount di hari yang dipilih.

Pada form input transaksi, terdapat stacked button yang berisi pilihan income dan expenses untuk menentukan jenis transaksi yang dilakukan. Kemudian terdapat floating label yang digunakan untuk mengisi tanggal transaksi, item, kategori, jumlah dan catatan jika ada, serta tombol simpan. Di bagian kanan bawah juga terdapat icon kamera yang dapat digunakan apabila user ingin menginput transaksi dengan fitur OCR. Tampilan form input dengan OCR dapat dilihat pada Gambar 12.

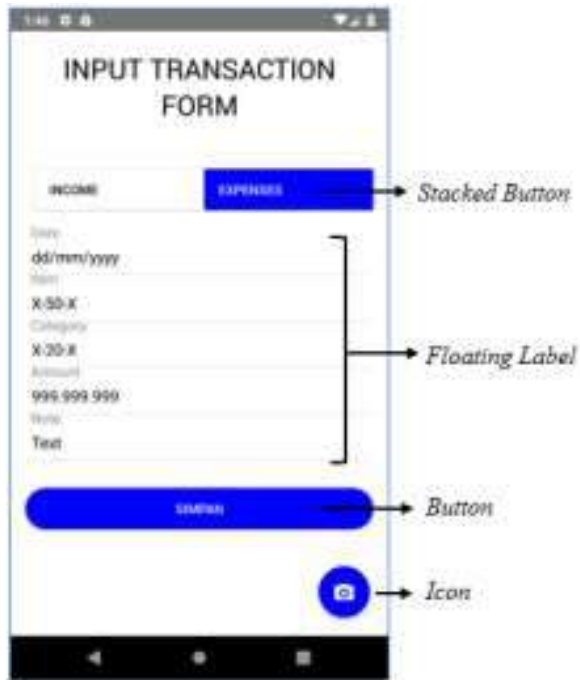

Gambar 11. Rancangan Form Input Transaksi

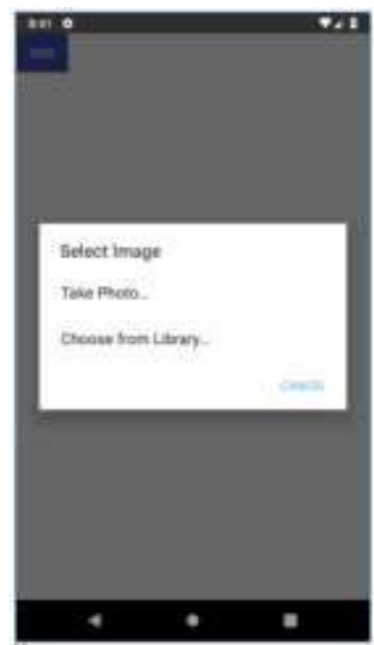

Gambar 12. Rancangan Form Input dengan OCR

Pada rancangan aplikasi money management ini juga terdapat form statistik yang terdiri dari stacked button kelompok waktu, picker berisi rentang waktu yang dapat dipilih user, serta piechart yang dilengkapi dengan legend. Selain itu terdapat pula stacked button income dan expenses agar user dapat memilih jenis transaksi yang ingin dilihat grafiknya.

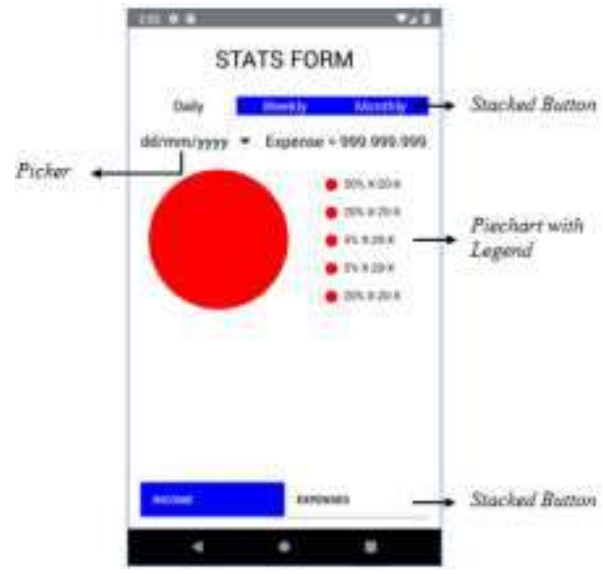

Gambar 13. Rancangan Form Statistik

\subsection{User Interface Aplikasi Money Management}

Pada tampilan registrasi, user akan diminta memasukkan username, email, password, confirm password, gender, date of birth. Selanjutnya user menekan tombol registrasi, kemudian sistem akan melakukan validasi terhadap data yang dimasukkan.

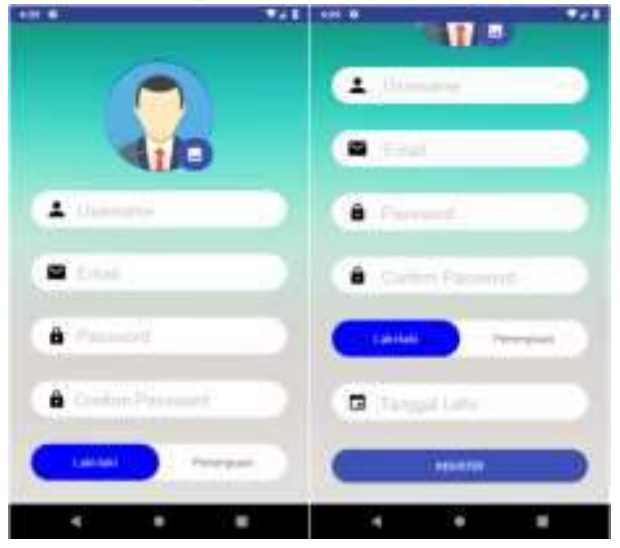

Gambar 14. Form Registrasi

Pada form transaksi mingguan dan bulanan akan ditampilkan data transaksi yang terjadi sesuai dengan rentang waktu yang dipilih oleh user. Jumlah pendapatan dan pengeluaran juga ditampilkan, serta selisih 
antara pendapat dan pengeluaran yang dilakukan oleh user pada rentang waktu yang dipilih.

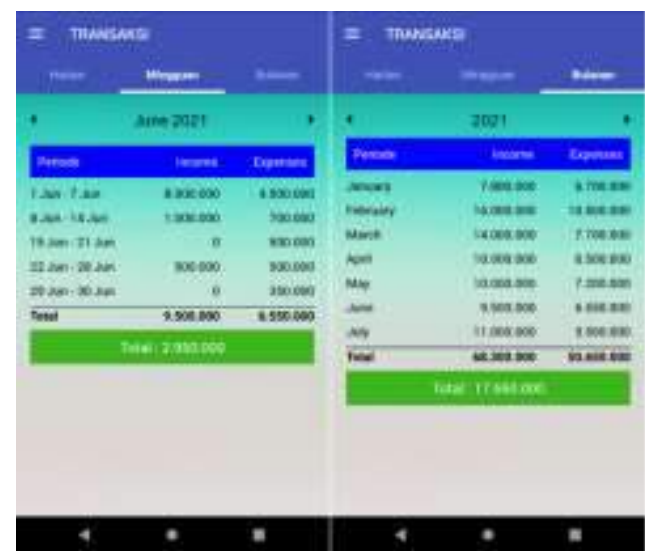

Gambar 15. Form Transaksi

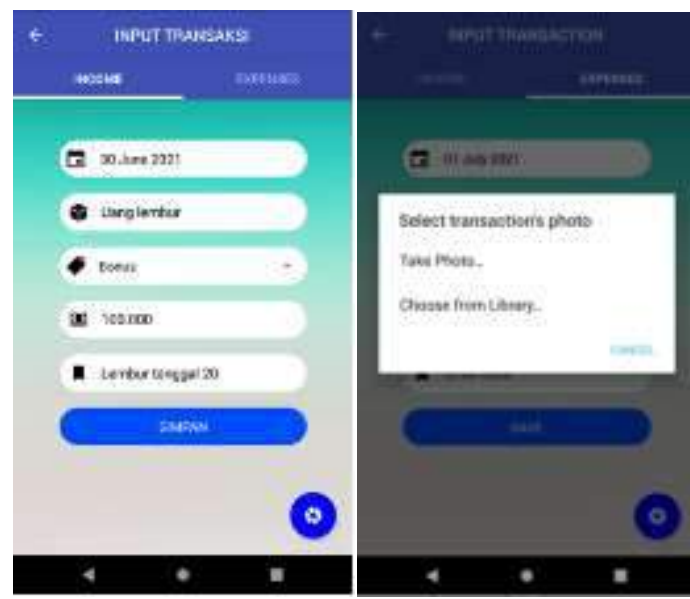

Gambar 16. Form Input Transaksi Manual \& OCR

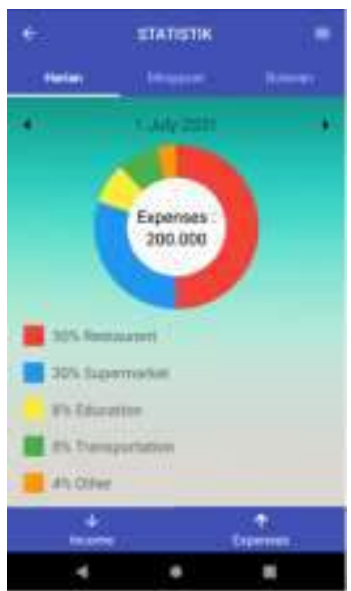

Gambar 17. Form Statistik

\subsection{Spesifikasi Sistem}

Aplikasi money management dijalankan di atas sistem operasi android, sehingga pengoperasiannya adalah dengan menggunakan smartphone. Adapun spesifikasi hardware dan software smartphone yang disarankan sebagai persyaratan untuk pengoperasian aplikasi money management adalah sebagai berikut:

Spesifikasi hardware smartphone yang disarankan untuk menjalankan aplikasi money management antara lain:

1) RAM 2 GB

2) Memori penyimpanan $32 \mathrm{~GB}$

3) Prosesor Octa-core $2.0 \mathrm{GHz}$

4) Layar 5.5 inches, $1080 \times 1920$ pixels

Spesifikasi software smartphone yang disarankan untuk pengoperasian aplikasi money management yaitu Android Operating System (OS) dengan versi minimal 6.0 Marshmallow.

\section{Kesimpulan}

Setelah melakukan studi literatur, analisis, perancangan, dan pengoperasian aplikasi money management yang dilakukan, didapatkan kesimpulan sebagai berikut:

1) Aplikasi yang dirancang dapat membantu user dalam melakukan manajemen keuangannya sehingga dapat membantu user dalam mengambil keputusan terkait keuangannya.

2) User dapat menggunakan aplikasi di setiap waktu dan di berbagai tempat.

\section{Saran}

Penulis berharap plikasi ini dapat dikembangkan lebih lanjut sesuai kebutuhan. Beberapa saran yang dapat diberikan penulis sebagai acuan untuk menghasilkan aplikasi yang lebih baik lagi, antara lain:

1) Menggabungkan OCR dengan API atau SDK sejenis terkait optimasi penyeleksi teks.

2) Menambahkan function yang dapat menentukan jenis gambar bukti transaksi.

3) Menambahkan fitur hubung ke akun lain sehingga dapat digunakan ke dalam skala yang lebih besar.

4) Menambahkan fitur hubung ke akun bank pribadi. 


\section{Daftar Pustaka}

[1] Noor, Agustian, and Syaiful Hadi.

"Aplikasi Manajemen Keuangan

Berbasis Web Dinas Komunikasi dan

Informatika Kabupaten Tanah Laut."

Jurnal Sains dan Informatika Volume

5, no. 1, 78-87, 2019

[2] Arka, Januari, Adam Hendra Brata, and Komang Candra Brata.

"Pengembangan Aplikasi Mobile

Manajemen Keuangan Dengan

Metode Scrum (Studi Kasus

Mahasiswa FILKOM UB)." Jurnal

Pengembangan Teknologi Informasi

dan Ilmu Komputer Vol. 3, no. 2,

pp.1199-1207, 2019.

[3] Raharjo, I. T., H. Puspitawati, and D.

Krisnatuti. "Tekanan Ekonomi,

Manajemen Keuangan dan

Kesejahteraan Pada Keluarga Muda."

Jurnal Ilmu Keluarga dan Konsumen

Vol.8, no. 1, pp. 38-48, 2015.

[4] Chaudhuri, Arindam , Krupa

Mandaviya, Pratixa Badelia, and

Soumya K Ghosh. Optical Character

Recognition Systems form Different

Languages with Soft Computing.

India: Springer, Cham, 2017.

[5] Bhatia, Neetu. "Optical Character

Recognition Techniques: A Review."

International Journal of Advanced
Research in Computer Science and

Software Vol 4, no. 5, pp. 1219-1223, 2014.

[6] Jubilee Enterprise. Mengenal Dasar-

Dasar Pemrograman Android.

Jakarta: Elex Media Komputindo,

2015.

[7] Eisenman, Bonnie. Learning React

Native: Building Native Mobile Apps

with JavaScript. California: O'Reilly

Media, 2017.

[8] Gill, Olivier. Using React Native for

Mobile Software Development.

Helsinki: Metropolia University of

Applied Sciences, 2018.

[9] McKinney, Donna B. Getting to

Know JavaScript. New York: Rosen

Publishing Group, 2019.

[10] Dixit, Prasanna Kumar. Android.

Noida: Vikas Publishing House, 2014.

[11] Lebanon,Guy and Mohamed El-

Geish.Computing wit Data: An

Introduction to the Data

Industry.USA:Springer,Cham,2018.

[12] Sukamto, Rosa Ariani, and M.

Shalahuddin. Rekayasa Perangkat

Lunak Terstruktur. Bandung:

Informatika, 2018. 